Jurnal Inkofar * Volume 1 No. 2, Desember 2017 * ISSN: 2615-3645 (Print) / 2581-2920 (Online)

Tersedia secara online di: http://www.politeknikmeta.ac.id/meta/ojs/

\title{
PENGEMBANGAN SISTEM INFORMASI BOOKING SERVICE MOTOR HONDA PADA PT. PACIFIC MOTOR II BEKASI BERBASIS WEB
}

\author{
Meta Litasari Sestiayunda ${ }^{1}$, Feri Prasetyo $\mathbf{H}^{2}$ \\ ${ }^{1}$ Manajemen Informatika, Program Diploma 3 AMIK BSI Bekasi, metalitasari@gmail.com \\ ${ }^{2}$ Manajemen Informatika, Program Diploma 3 AMIK BSI Bekasi, feriphd@gmail.com
}

\begin{abstract}
Information System Development Booking is the result of technological development of a computer application that will be expected to help and facilitate human work. It is also hoped that this system can be fostered in daily activities to be effective and efficient. This research focuses on booking service or ordering for Honda motorcycle service at PT. Pacific Motor II Bekasi. Where is PT. Pacific Motor II requires the existence of an integrated system change in the form of information systems that support and provide information services workshop for the wider community considering the increasing need for the maintenance of vehicles, especially motorcycles. With the application program is expected to help people to more easily get information and make a booking service. The design of this booking service program starts from the design of the program in the form of Entity Relationship Diagram design with five supporting tables, along with Logical Structur Record, Navigation Structure consisting of admin and visitor, until program testing is done to adjust the application whether it is easy in gunkaan or not based on preference of the respondents. Making this program using Dreamweaver CS6 as an application for web designing, XAMPP v.3.2.1 as local server and PHPMyAdmin. The research method used in the development method of waterfall software and descriptive method.
\end{abstract}

Keywords : Information Systems, Booking service, Web

ABSTRAK

Pengembangan Sistem informasi Booking merupakan hasil perkembangan teknologi sebuah aplikasi komputer yang nantinya diharapkan dapat membantu dan memudahkan pekerjaan manusia. Diharapkan pula sistem ini dapat membatu dalam kegitan sehari hari agar dapat efektif dan efisiensi, Penelitian ini berfokus pada booking service atau pemesanan untuk servis sepeda motor Honda pada PT. Pacific Motor II Bekasi. Dimana PT. Pacific Motor II membutuhkan sekali adanya suatu perubahan sistem yang terintegrasi berupa sistem informasi yang menunjang dan memberikan pelayanan informasi bengkel bagi masyarakat luas mengingat meningkatnya kebutuhan masyarakat akan perawatan kendaraan khususnya sepeda motor. Dengan adanya program aplikasi ini diharapkan dapat membantu masyarakat agar lebih mudah mendapat informasi dan melakukan booking service. Perancangan program booking service ini dimulai dari pembuatan desain program berupa desain Entity Relationship Diagram dengan lima tabel pendukung, beserta Logical Structur Record, Struktur Navigasi yang terdiri dari admin dan pengunjung, sampai pengujian program yang dilakukan untuk menyesuaikan aplikasi apakah mudah digunakan atau tidak berdasarkan preferensi dari responden. Pembuatan program ini menggunakan Dreamweaver CS6 sebagai aplikasi untuk merancang web, $X A M P P$ v.3.2.1 sebagai server lokal dan PHPMyAdmin. Metode penelitian yang di gunakan mengunakan metode pengembangan perangkat lunak waterfall dan metode deskriptif.

Kata Kunci : Sistem Informasi, Booking service, Web

\section{PENDAHULUAN}

PT. Pacific Motor II Bekasi merupakan perusahaan yang bergerak di bidang penjualan, perawatan dan penyedia suku cadang sepeda motor Honda. Untuk mengimbangi teknologi yang semakin berkembang, maka diperlukan suatu pengelolaan manajemen perusahaan yang baik serta peningkatan pada sumber daya manusia. PT. Pacific Motor II Bekasi, dimana sebagai salah satu bengkel resmi sepeda motor Honda yang ada di kota Bekasi, juga memiliki strategi dan keunggulan yang berbeda dibanding pesaing yang ada. Kepuasan pelanggan merupakan suatu hal yang sangat positif demi mempertahankan keberadaan pelanggannya tersebut untuk tetap berjalannya suatu bisnis atau usaha. 
Adapun sistem berjalan di PT. Pacific Motor II Bekasi khusunya pada saat booking service motor di bengkel masih dilakukan secara manual dimana para pelanggan datang langsung ke bengkel untuk mengantri dan mendaftarkan service motor yang akan memakan waktu. Dan hal ini terkadang membuat petugas pelayanan service tidak akurat dalam penginputan data-data pelanggan sehingga data service menjadi tercecer. Oleh karena itu, penulis membuat sistem usulan berupa booking service motor berbasis web. Dengan adanya sistem booking service motor secara online, maka pelanggan akan lebih mudah dalam memesan antrian untuk service. Selain itu hal ini akan memudahkan petugas pelayanan service dalam pencarian history service pelanggan dan juga bisa dijadikan acuan sebagai pengingat untuk jadwal service berikutnya. Dampak positif yang diharapkan berikutnya adalah untuk meningkatkan unit entry setiap bulannya bagi bengkel. Karena pemilik tidak hanya memiliki satu cabang bengkel saja, tentu hal ini juga dapat mempermudah pemilik perusahaan untuk mengelola bengkel pusat dengan bengkel cabang.

\section{LANDASAN TEORI}

2.1 Penelitian sebelumnya

Pada penelitian sebelumnya di lakukan oleh jayanti (2012) pada jurnal Ilmu informasi perpustakaan dan kearsipan, Perancangan web yang di rancang bersifat statis, desainnya menggunakan program Adobe Dreamweaver CS5. Dimana mengunakan xampp yang berlaku sebagai server local dan Adobe Dreamweaver berlaku sebagai sofware untuk membuat dan membuat database, membuat site web, membuat halaman dan menu web, mendesain warna, membuat link, menginput informasi, sehingga didapatkan hasil akhir dari pendesainan web

2.2 Web

World Wide Web (www) atau yang biasa dikenal sebagai website menurut Edy Irwansyah dan V.Jurike Moniaga (2014:34), merupakan salah satu layanan yang didapat oleh pemakai komputer yang terhubung ke internet. Secara singkat pengertian web adalah kumpulan halaman yang menyediakan informasi.

2.3 Adobe dreamweaver CS6

Menurut Madcoms (2013:1), adalah perangkat lunak terkemuka untuk desain web yang menyediakan kemampuan visual yang intuitif termasuk pada tingkat kode, yang dapat digunakan untuk membuat dan mengedit website HTML serta aplikasi mobile seperti smartphone, tablet, dan perangkat lainnya.

\subsection{XAMPP}

Menurut Bunafit Nugroho (2014:1) "Xampp server adalah paket software web server yang di dalamnya sudah ada software Apache, PHP dan MySQL

2.5 Basisdata

Basis data menurut Jeperson Hutahean (2014:50), merupakan kegiatan sistem program komputer untuk berbagi aplikasi komputer.

2.6 Struktur Navigasi

Menurut Binanto (2010a:268) "Struktur navigasi adalah gabungan dari struktur referensi informasi situs web dan mekanisme link yang mendukung untuk pengunjung yang melakukan penjelajahan situs

\section{METODE PENELITIAN}

3.1 Model waterfall menurut Rosa dan Shalahudin (2015:28) sering juga disebut model sekuensial linier (sequential linear) atau alur hidup klasik (classic life cycle). Model air terjun menyediakan pendekatan alur hidup perangkat lunak secara sekuensial atau terurut dimulai dari analisis, desain, pengodean, pengujian, dan tahap pendukung (support)

3.2 Metode Deskriptif suatu metode yang mengambarkan suati fenoena kegiatan yang terjadi didalam Deskriptif, dimana penelitian dimaksudkan untuk membuat pemerian/penyandraan secara sistematis, faktual dan akurat mengenai fakta-fakta dan sifat-sifat populasi tertentu (Akbar, 2003:4). 


\section{PEMBAHASAN}

Seperti yang sudah diterangkan di awal bahawa sistem pelayanan service sepeda motor pada PT Pasific Motor 2 masih mengunakan sistem manual dadalm arti semua kegiatan dilakukan dengan pencatatan tanpa adanya program dan database ayng sudah ada. Dari kegiatan di atas pengembangan sistem booking service dilakukan agar mempermudah kegiatan pelayanan yang ada di PT Pasific Motor.

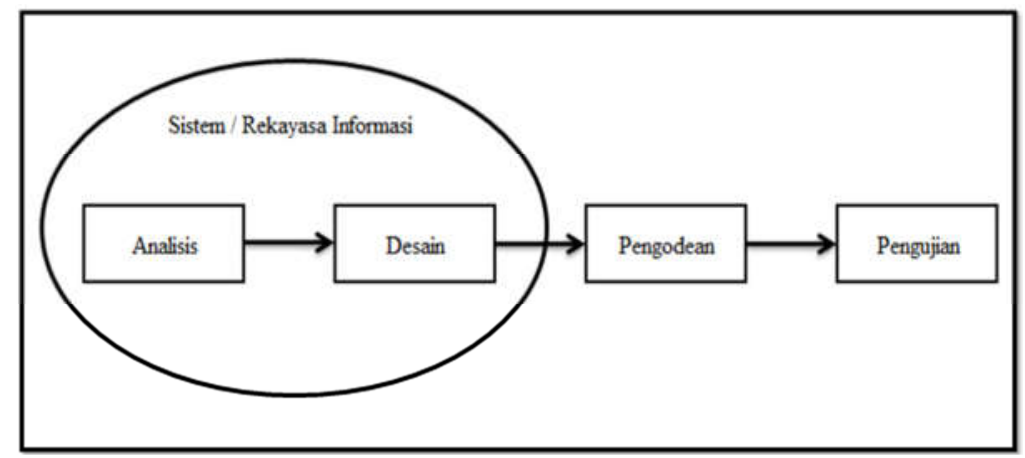

Gambar 1. Alur waterfall

Alur desain sistem pengembangan perangkat lunak sebagai berikut:

4.1 ANALISA KEBUTUHAN

Analisa kebutuhan merupakan penjabaran yang dilakukan dalam pemetaan kebutuhan yang ada pada web sistem informasi ini berupa kebutuhan dari sisi pengguna, pengunjung, dan sistem itu sendiri.

1. Analisis Kebutuhan Pengguna antara lain

a) Administrator

Admin dapat mengakses halaman front end dan back end pada website. Pada bagian back end, admin dapat meng-update website dengan melakukan login pada halaman administrator terlebih dahulu.

b) Pengunjung

Pengunjung hanya dapat mengakses halaman front end pada website untuk melakukan proses booking service tanpa harus login terlebih dahulu.

2. Analisis Kebutuhan Sistem

a) Pada bagian front end website ini, terdapat beberapa menu yaitu :

i. Menu Home

ii. Menu Tentang Kami

iii. Menu Booking Service

iv. Menu Kontak

b) Pada bagian back end website ini, terdapat beberapa menu yaitu :

i. Menu Master
a. Pengguna
b. $\quad$ Menu Booking
c. Menu Berita

ii. Menu Transaksi

a. Reservasi Online

b. Pesan Masuk

iii. Menu Laporan

\subsection{DESAIN}

a. Reservasi Online

b. Daftar Jasa

Desain merupakan rancangan dari sistem yang akan di buat guna merelasikan tahapan tahapan pada setiap modul agar berelasi sesuai dengan kebutuhan antara lain:

1. Struktur navigasi

Struktur navigasi digunakan sebagai rancangan alur dari web yang akan di tampilkan dimana

berisi modul modul. Terdiri dari 2 Truktur satu buat admin dan satu untuk pengunjung. 
a. Navigasi Admin

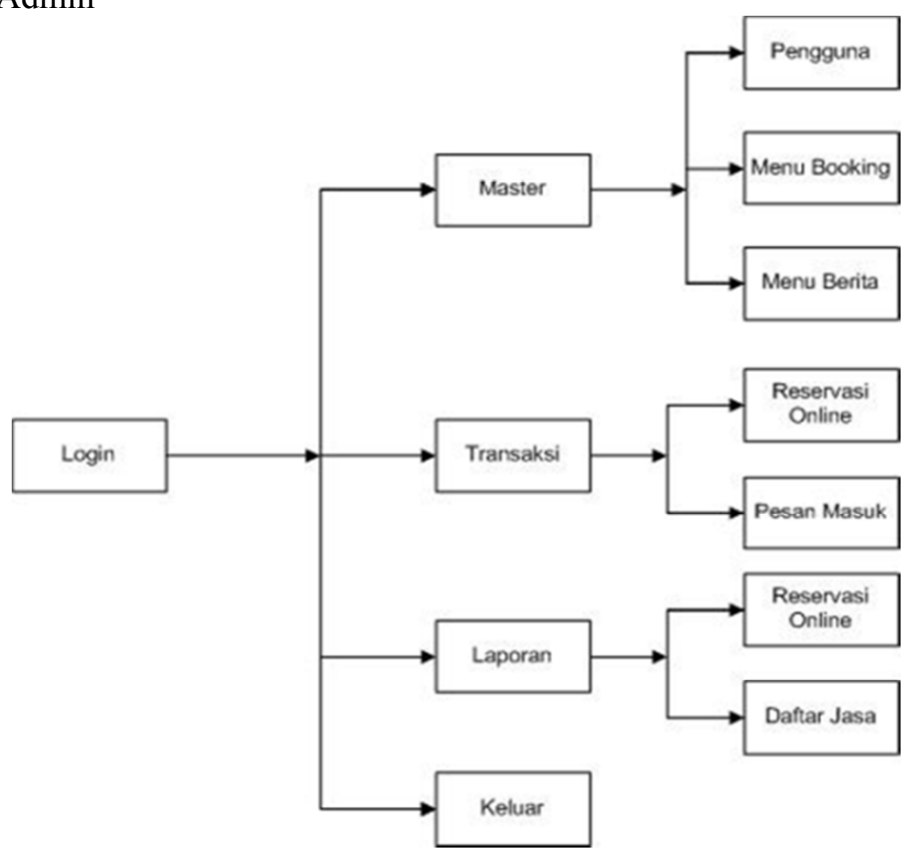

Gambar 2. navigasi admin

b. Navigasi pengunjung

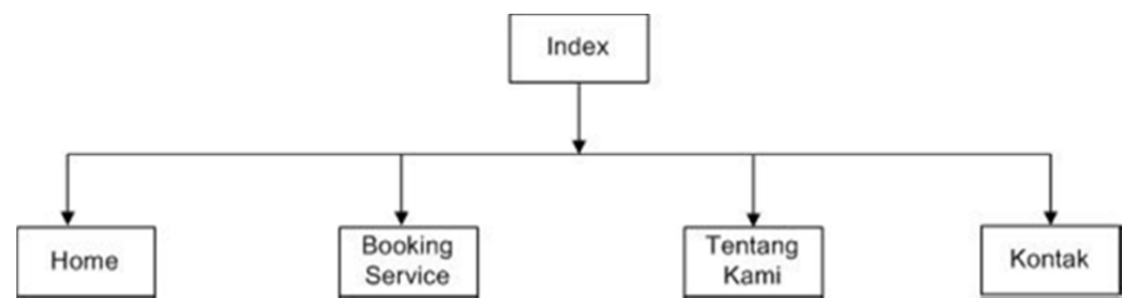

Gambar 3. navigasi pengunjung

2. Perancangan Perangkat Lunak

a. Halaman Home

Halaman home merupakan halaman menu yang menjadi tampilan utama website ini. Pada halaman ini menampilkan berita - berita terkini yang berkaitan dengan otomotif ataupun event di PT.Pacific Motor II.

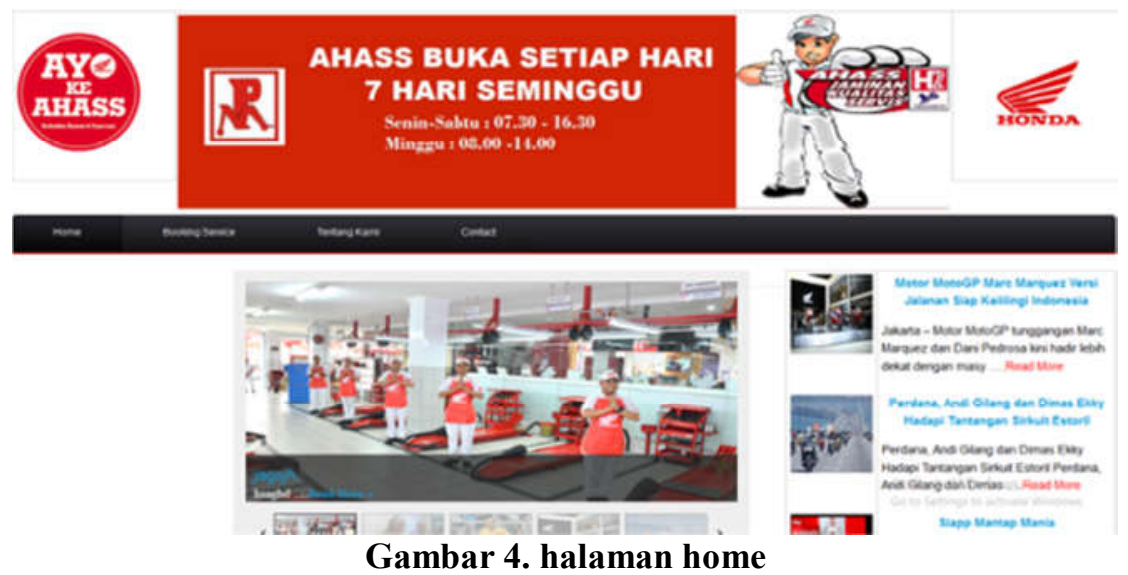


b. Halaman Booking

Pada halaman ini menampilkan form untuk pengunjung melakukan booking service, dimana pengunjung dapat memilih jam dan hari kapan akan melakukan service

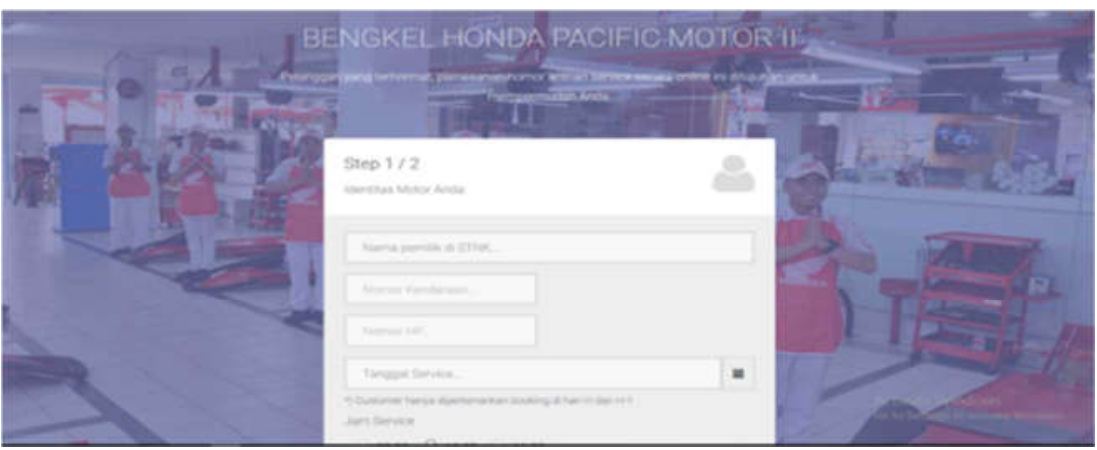

Gambar 5. halaman booking

c. Halaman Profil

Pada halaman ini berisi tentang profil PT. Pacific Motor II dimana berisi tentang profil perusahaan mulai dari sejarah terbentuknya hingga saat ini beserta penghargaaan pa saja yang telah di raih hingga saat ini.

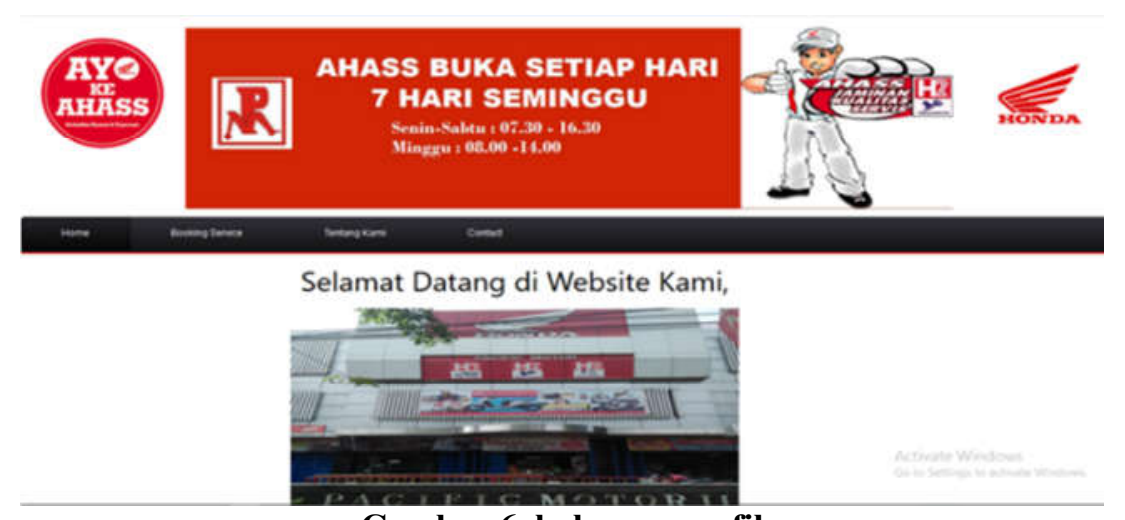

Gambar 6. halaman profil

d. Halaman Pesan

Pada halaman ini pengunjung dapat mengirim pesan baik berupa pertanyaan, kritik maupun saran untuk bengkel.



Hubungi Kami

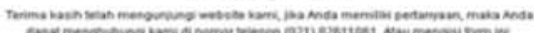

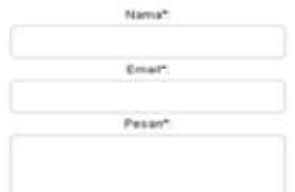

Gambar 7. halaman pesan 
e. Halaman Admin

Pada halaman ini administrator dapat login untuk mengakses database
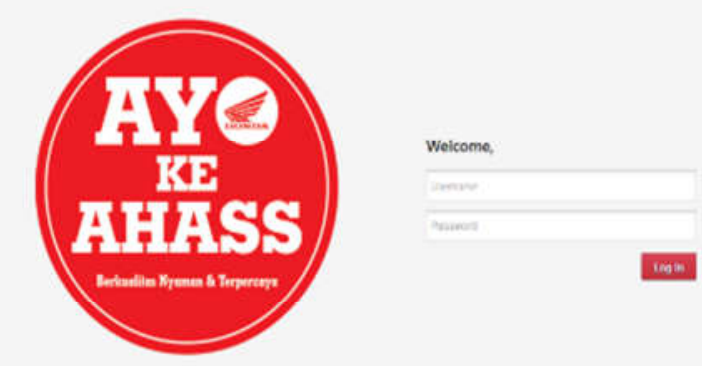

\section{Gambar 8. login admin}

f. Input data penguna

Pada halaman ini admin dapat menginput data pengguna yang dapat mengakses halaman admin dengan tampilan form inputan berupa user name, password, nama legkap, level dan status blokir.

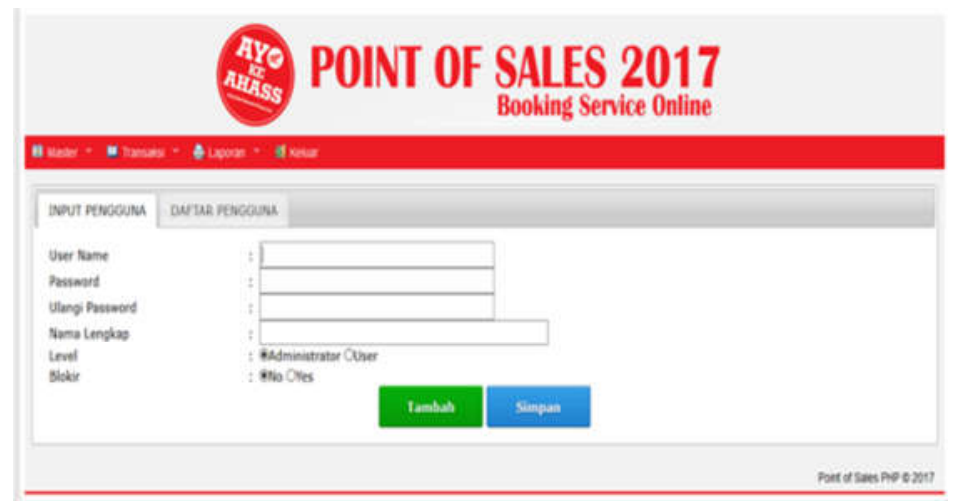

\section{Gambar 9. input data pengguna}

g. Data penguna

Pada halaman ini admin dapat melihat data pengguna yang dapat mengakses halaman admin



Gambar 10. data penguna 
h. Harga Service

Pada halaman ini admin dapat menginput dan mengedit data harga service untuk estimasi di halaman booking service pengunjung.

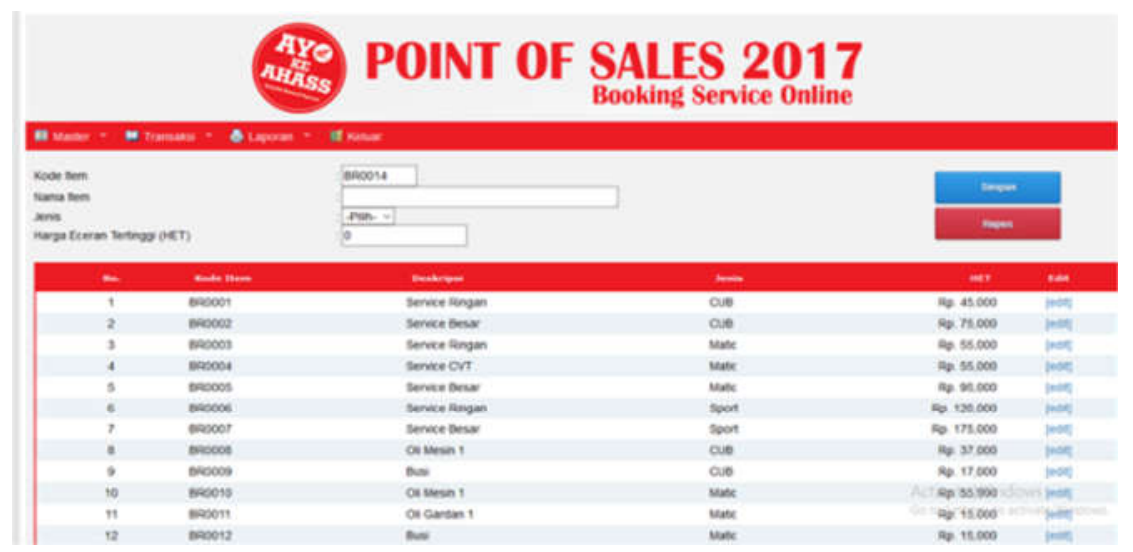

Gambar 11. halaman service

i. Halaman Transaksi - Reservasi Online

Pada halaman ini admin dapat melihat dan menghapus data pengunjung yang melakukan booking service

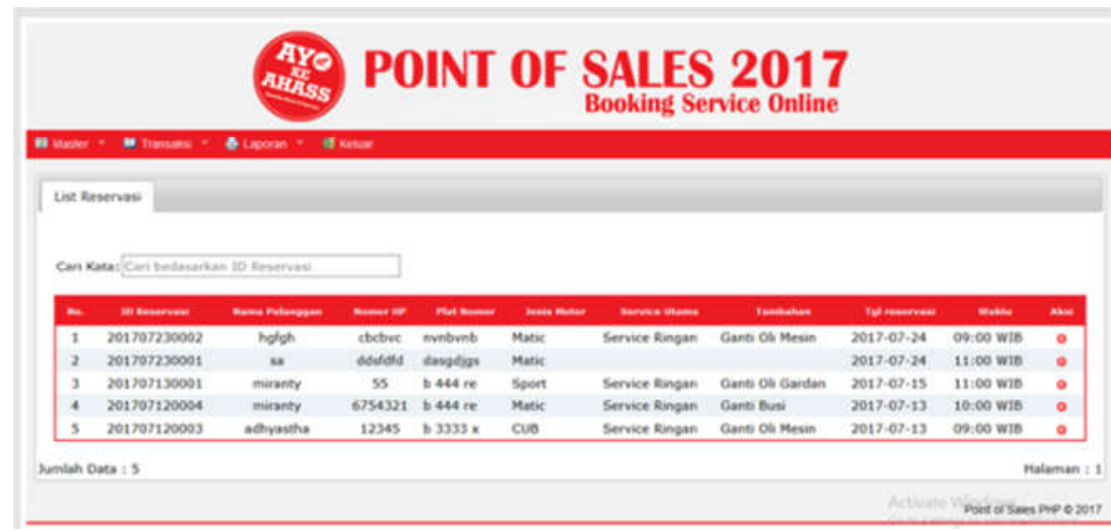

Gambar 12. Halaman Reservasi

j. Halaman Transaksi - Pesan Masuk

Pada halaman ini admin dapat melihat pesan yang masuk dari

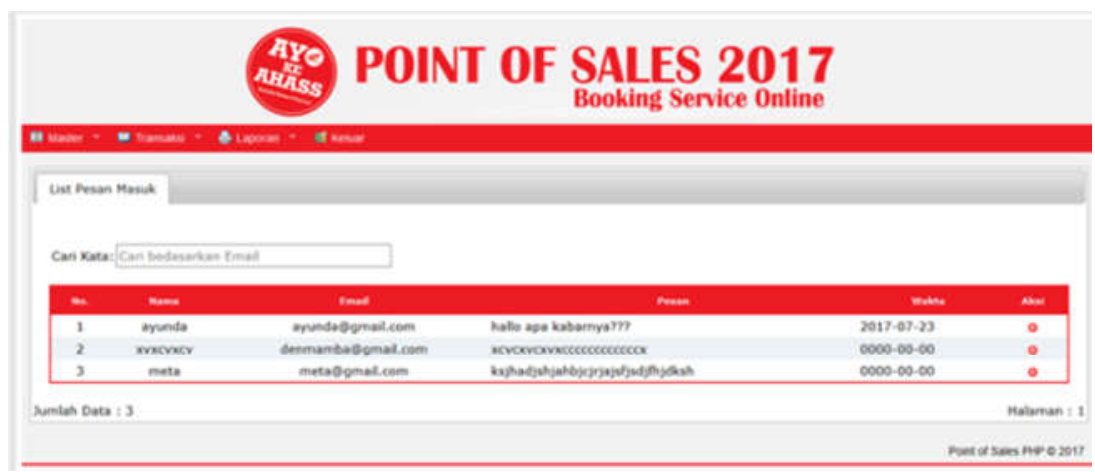

Gambar 13. Halaman Transaksi 
Jurnal Inkofar* Volume 1 No. 2, Desember 2017 * ISSN: 2615-3645 (Print) / 2581-2920 (Online)

Tersedia secara online di: http://www.politeknikmeta.ac.id/meta/ojs/

k. Halaman Laporan - Daftar Jasa

Pada halaman ini admin dapat membuat laporan data harga jasa service yang dapat dicetak ke dalam lembar kerja $M S$. Excel.

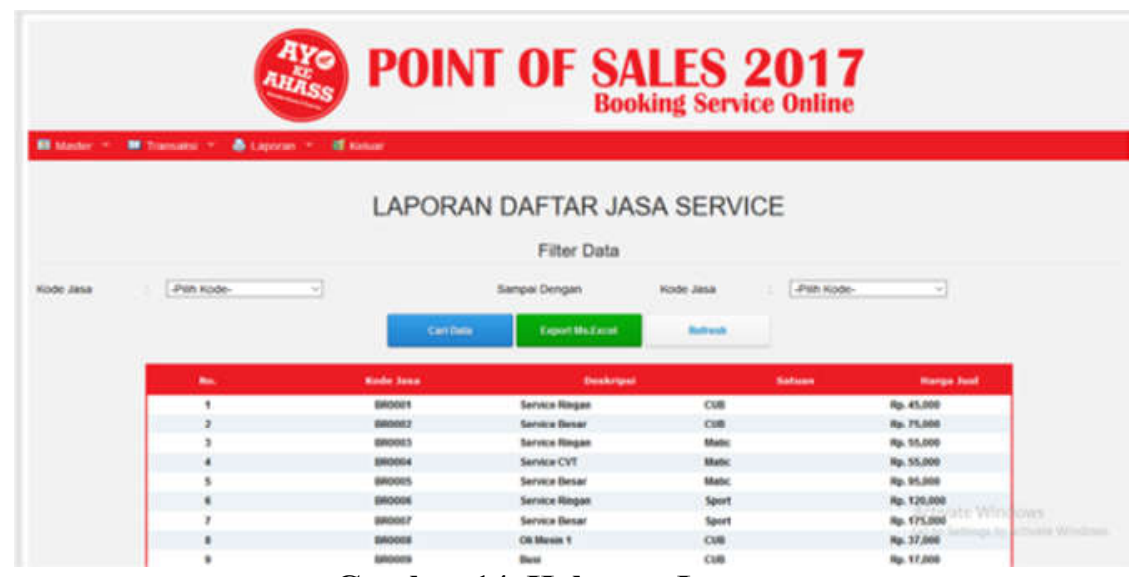

Gambar 14. Halaman Laporan

3. Sistem Basis Data

a. ERD



Gambar 15. ERD

b. LRS

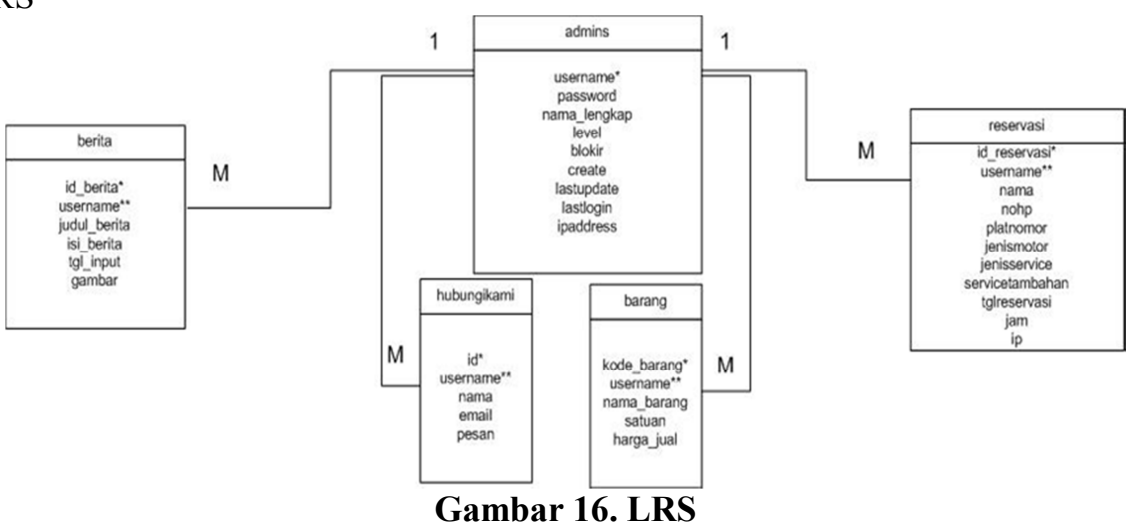




\subsection{PENGKODEAN}

Penkodean merupakan proses perubahan karakter dari data yang di gunakan untuk membaca sistem komputer, pada pengkodean ini mengunakan kode grup.

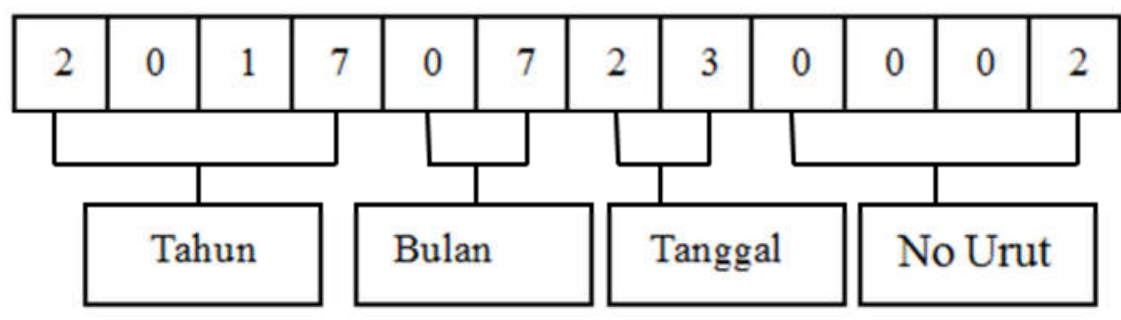

Gambar 17. kode booking

Kode diatas terdiri dari 12 digit dimana digit 1-4 merupakan tahun 2017 booking, digit ke 5 dan 6 merupakan bulan booking yaitu bulan Juli, Digit 7 dan 8 merupakan tanggal booking, digit ke 9-12 nomorurut booking.

\subsection{PENGUJIAN}

1. Reponden

Responden yang melakukan uji blackbox testing ini web ini merupakan karyawan ahhas sebanyak 8 orang dan para pengunjung ahas sebanyak 20 0rang, dengan mengisi 10 pernyataan mengenai web yang akan di uji coba, untuk mengetahui seberapa besar web ini dapat di gunakan oleh responden.

a) Karyawan AHASS

Tabel 1. Presentasi preferensi karyawan

\begin{tabular}{ccccc}
\hline Pernyatan & \multicolumn{2}{c}{ Pemilih } & \multicolumn{2}{c}{ Presentase } \\
\cline { 2 - 5 } & Ya & Tidak & Ya & Tidak \\
\hline 1 & 6 & 2 & $75 \%$ & $25 \%$ \\
\hline 2 & 5 & 3 & $62 \%$ & $38 \%$ \\
\hline 3 & 6 & 2 & $75 \%$ & $25 \%$ \\
\hline 4 & 6 & 2 & $75 \%$ & $25 \%$ \\
\hline 5 & 5 & 3 & $62 \%$ & $38 \%$ \\
\hline 6 & 7 & 1 & $87 \%$ & $13 \%$ \\
\hline 7 & 6 & 2 & $75 \%$ & $25 \%$ \\
\hline 8 & 7 & 1 & $87 \%$ & $13 \%$ \\
\hline 9 & 6 & 2 & $75 \%$ & $25 \%$ \\
\hline 10 & 7 & 1 & $87 \%$ & $13 \%$ \\
\hline
\end{tabular}

Dari 10 pernyataan di atas respon karyawan terhadap point pertama hingga point ke $10 \mathrm{di}$ atas hanya pada point 5 responden memilih ya $62 \%$. Sedangkan yang memilih tidak di bawah $38 \%$. 
Jurnal Inkofar * Volume 1 No. 2, Desember 2017 * ISSN: 2615-3645 (Print) / 2581-2920 (Online)

Tersedia secara online di: http://www.politeknikmeta.ac.id/meta/ojs/



Gambar 18. grafik responden karyawan

b) Pengunjung

Tabel 2. Presentasi preferensi Pengujung

\begin{tabular}{ccccc}
\hline Pernyataan & \multicolumn{2}{c}{ Pemilih } & \multicolumn{2}{c}{ Presentase } \\
\cline { 2 - 5 } & Ya & Tidak & Ya & Tidak \\
\hline 1 & 15 & 5 & $75 \%$ & $25 \%$ \\
\hline 2 & 14 & 6 & $70 \%$ & $30 \%$ \\
\hline 3 & 16 & 4 & $80 \%$ & $20 \%$ \\
\hline 4 & 14 & 6 & $70 \%$ & $30 \%$ \\
\hline 5 & 13 & 7 & $65 \%$ & $35 \%$ \\
\hline 6 & 17 & 3 & $85 \%$ & $15 \%$ \\
\hline 7 & 16 & 4 & $80 \%$ & $20 \%$ \\
\hline 8 & 16 & 4 & $80 \%$ & $20 \%$ \\
\hline 9 & 14 & 6 & $70 \%$ & $30 \%$ \\
\hline 10 & 13 & 7 & $65 \%$ & $35 \%$ \\
\hline
\end{tabular}

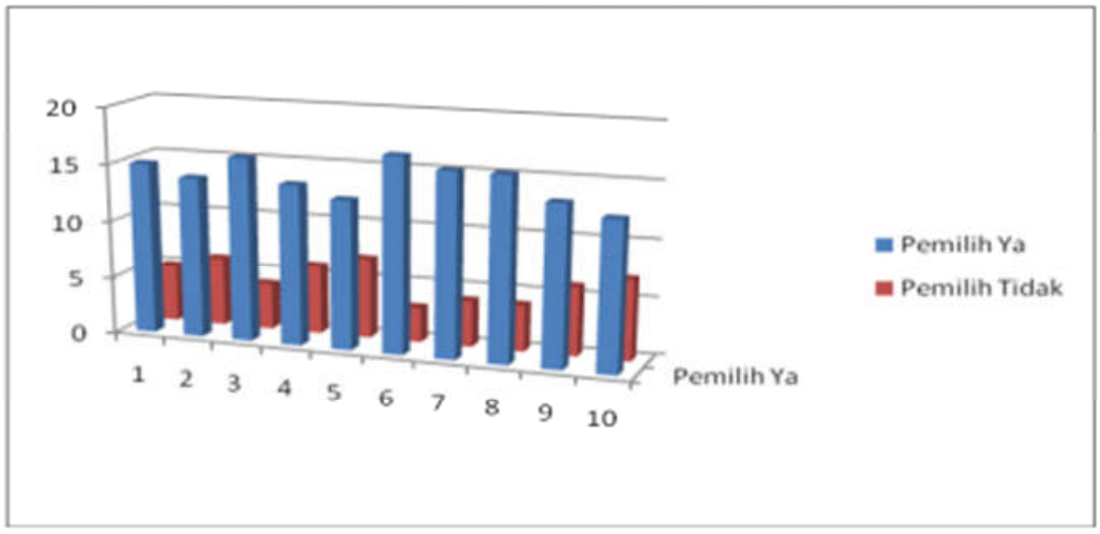

Gambar 19. grafik responden pengunjung 
Jurnal Inkofar * Volume 1 No. 2, Desember 2017 * ISSN: 2615-3645 (Print) / 2581-2920 (Online)

Tersedia secara online di: http://www.politeknikmeta.ac.id/meta/ojs/

\section{KESIMPULAN}

1. Pengenbangan sistem informasi booking service ini merupakan pengembangan sistem informasi layanan service sepeda motor yang di alihnya dengan mengunakan web, Rancangan Website ini dibagi menjadi dua bagian yaitu halaman administrator yang dapat diakses oleh administrator dan halaman website yang dapat diakses oleh pengguna.

2. Dengan adanya Tampilan halaman khusus administrator dimungkinkan pekerjaan mengelola data service yang akan ditampilkan dalam website menjadi mudah. Pada kegiatan ini Admin cukup menggunakan menu-menu yang tersedia dan bisa langsung melakukan aksi yang diinginkan.

3. Dengan adanya situs website ini Bengkel Honda Pacific Motor II Bekasi dapat dengan mudah mempromosikan diri dengan jangkauan yang lebih luas kepada masyarakat. Selain itu Sebagai sarana untuk memudahkan masyarakat yang ingin booking service tanpa harus datang dulu ke bengkel dan mengantri cukup lama.

4. Respon dari pengunjung Ahas sat melakukan uji coba web ini dari 10 point yang di ajukan rata rata di atas $65 \%$ ini menandakan bahwa antusiasme dari pengunjung akan layanan ini mendapat respon yang positif. Begitu sebaliknya pula dari sisi karwayan ahhas mendapat respon yang positif.

\section{DAFTAR PUSTAKA}

AL-Bahra Bin Ladjamudin. 2006. Analisis dan Desain Sistem Informasi.

Hutahean, Jeperson. 2014. Konsep Sistem Informasi. Yogyakarta : Deepublish

Iwan Binanto. 2010. Multimedia Digital Dasar Teori dan Pengembangannya. Yogyakarta

Kun, Tony. 2010. Membuat Website Canggih dengan JQuery untuk Pemula. Jakarta: Mediakita.

Kurniawan, Dedik. 2010. Website Pencetak Uang. Jakarta : PT. Elex Media Komputindo

Madcoms. 2013. Kupas Tuntas Adobe Dreamweaver CS6 dengan Pemrograman PHP \& MySQL.Yogyakarta : Andi.

Moniaga,V.Jurike dan Edy Irwansyah. 2014. Pengantar Teknologi Informasi. Yogyakarta : Deepublish

Nugroho, Bunafit. 2014. Panduan Proyek Membuat Website Toko Online dengan PHP, MySQL dan Dreamweaver. Yogyakarta : PT. Alif Media

Ramadhan, Arief. 2005. Seri Pelajaran Komputer Internet dan Aplikasinya. Jakarta : PT. Elex Media Komputindo

Shalahudin,M. dan Rosa A.S. 2015. Rekayasa Perangkat Lunak. Bandung : Informatika

Anhar. 2010. Panduan Menguasai PHP \& MySQL Secara Otodidak. Jakarta : mediakita

Suryana, Taryana dan Koesheryatin. 2014. Aplikasi Internet Menggunakan HTML, CSS, \& JavaScript. Jakarta: PT. Elex Media Komputindo.

Jayanti Susan, Malta Nelisa 2012 Perancangan Web Sebagai Media Promosi Koleksi Naskah Kuno Minangkabau di Museum Adityawarman Sumatera Barat. Jurnal ilmu informasi perpustakaan

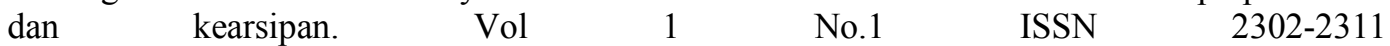
http://ejournal.unp.ac.id/index.php/iipk/article/view/1512 